\title{
Insulin Resistance and Glucose Intolerance in HIV Infected Children on Antiretroviral Therapy at Lubango Pediatric Hospital- Angola
}

\author{
Ketha Francisco ${ }^{1,2^{*}}$, Beatriz Pole ${ }^{1}$, Sandra Tchiva ${ }^{1}$, Thomas Ngwiri ${ }^{2}$, Ruth Nduati ${ }^{3}$, Lucy Mungai ${ }^{3}$, \\ David Gathara ${ }^{4}$ and Habbas Qadreh ${ }^{5}$
}

\author{
${ }^{1}$ Paediatric Hospital of Lubango, Angola \\ ${ }^{2}$ Pediatric Endocrine Training Centre for Africa, Kenya \\ ${ }^{3}$ University of Nairobi, Kenya \\ ${ }^{4}$ Kenya Medical Research Institute, Kenya \\ ${ }^{5}$ Athens Paediatric Centre, Greece
}

*Corresponding author: Ketha Francisco, Jomo Kenyatta University of Agriculture and Technology, Paediatric Hospital of lubango-Angola, Tel: +244923715091

\section{Abstract}

Introduction: Antiretroviral therapy (ART) has proved to be an important intervention in the reduction of both morbidity and mortality of HIV infected patients. As the use of ART increases, a number of studies have associate it to some metabolic complications including glucose intolerance, dyslipidaemia, and diabetes mellitus. Despite the high prevalence of HIVIAIDS in Africa and the recent increased access to Antiretroviral drugs, information on ART related insulin resistance and glucose metabolism in the African population including children is scarce if not almost non-existent posing a barrier to implementation of a monitoring plan in Angola.

Objective: To describe the pattern of insulin resistance and glucose metabolism among HIV infected children on ART between 3-14 years of age at Lubango paediatric hospital.

Methods: The study adopted a Cross-sectional study design and data were collected using an interviewer administered questionnaire, clinical examination and anthropometric measurements of HIV infected children on ART.

Venous blood sample was obtained for fasting blood glucose and fasting insulin and HOMA-IR was calculated, followed by an Oral glucose tolerance test as per World Health Organization guidelines.

Result: In this study, $40 \%$ (20) and 20\% (10) of the children had an OGTT and calculated HOMA-IR of more than 7.8 $\mathrm{mm} / \mathrm{l}$ and 1.999 respectively.
\end{abstract}

In the bivariate analysis, children who had history of diabetes in the family were significantly more likely to have Insulin Resistance ( $p$ 0.027). Female sex ( $p$ 0.038), advanced clinical stage of the AIDS disease $(p<0.001)$ had a strong association with abnormal OGTT while long time on ARV were moderately associated with abnormal OGTT ( $p$ 0.057).

Conclusion: There is a high prevalence of insulin resistance and glucose intolerance among HIV positive children on ART on follow up at Lubango paediatrics hospital. Insulin resistance was associated with family history of Diabetes white glucose intolerance was associated with female sex, advance stage of AIDS and long time on antiretroviral therapy.

\section{Introduction}

In 2015 UNAIDS estimated that 2.1 million of HIV infected patient and about 1 million who died due to AIDS related conditions were under 15 years of age, the majority in sub Saharan Africa (SSA) [1]. Worldwide 91\% of the estimated 370,000 new HIV infections are children $<15$ years living in SSA. Untreated HIV infected children have a high mortality during early infancy, which has been estimated to be around $75 \%$ by 5 years of age [2]. Among perinatally infected children initiation of antiretroviral therapy (ART) before 7 weeks of 
life is associated with a $>60 \%$ reduction in mortality [3]. In addition, early ART initiation protects the infected children neurocognition, and protects them from other complications associated with chronic untreated HIV disease [4]. Currently the global strategy implemented in many countries is to start ART in children as soon as the diagnosis is made with a global goal to provide it to at last $80 \%$ of the children in need [5]. The government of Angola like many countries in sub-Saharan Africa now provides ART drug free of charge, leading to increase prescription of the same to adults and children in need. Antiretroviral therapy has then proved to be an important intervention in the reduction of both morbidity and mortality of HIV infected patients. There are emerging evidences of metabolic adverse events associated with the use of ART which include among others glucose intolerance, dyslipidaemia, and diabetes mellitus $[6,7]$. The most commonly implicated group of drugs are the Protease inhibitors (PIs) and Nucleoside reverse transcriptase inhibitors (NRTI's), both of which are postulated to increase insulin resistance. Factors that contribute to the abnormal insulin resistance in HIV infected children are still poorly understood. PIs directly and/or indirectly modify body fat composition, lipid profile, quality and quantity of Adipokine and other pro and anti-inflammatory mediators [8]. Further to this, fat redistribution is commonly observed in patient using these drugs. It is postulated that there is an association with insulin resistance. The potential of NRTI's to alter mitochondrial function and to influence insulin sensitivity has also been reported [9]. So our current challenge when dealing with HIV infected patients should include not only identification and monitoring them for co-morbid risk factors but as well monitor health related risks associated with its treatment and long term survival, principally for children who will have to take these drugs for long time. Metabolic comorbid risks including among others glucose intolerance, dyslipidaemia, diabetes mellitus, metabolic syndrome and others are increasingly seen in people on long term ART and pose a significant threat to the gain in decreased morbidity and mortality of people living with HIV. Both HIV and diabetes Mellitus are chronic condition that significantly affect at the same time the style and quality of living of affected human being. When these two diseases coexist, their treatment would be overwhelming for patients and their side effect difficult to control.

In Angola and in most of the African's countries with similar genetic and socio-demographic background, the association of ART and insulin resistance has not been well studied in the paediatric group.

\section{Materials and Methods}

A Cross sectional study was carried out between January and March 2019 at lubango pediatric hospital- Angola, located in lubango/Area Helder Neto (the core of the city) and occupies an area of 1998-meter square. The hospital has a capacity of 250 beds and admits about 6783 children annually. It has a comprehensive care center (CCC) for routine counselling, diagnosis, treatment and monitoring of HIV infected children. The CCC has 348 patients on follow up in which 194 are between 3 and 14 years and on antiretroviral therapy (lubango pediatric hospital record 2017). Children aged 3-14 years of age, HIV positive on a stable ART for at least 1 year, on follow up at lubango pediatric hospital- CCC were our study subject. The minimum sample size was 47 as determined using the Fishers formula and finite population correction factor.

\section{Data Collection Tool and Equipment}

Data were collected using an interviewer administered structured questionnaire. The respondents who were the mothers/caretakers/guardians of children. 50 pairs (caretaker-child) were systematically recruited into the study. Complete Clinical examination was conducted by a trained Medical Doctor. Anthropometric measurements such as weight, height/length and Mean Upper Arm Circumference (MUAC) were also obtained from the study subjects following by a Body Mass Index (BMI) calculation. This was conducted using weighing scale, heightometer and pediatric MUAC tapes. Venous blood sample was obtained for fasting blood glucose and fasting insulin. Homeostatic Model Assessment for Insulin Resistance (HOMA-IR) was calculated, followed by an Oral glucose tolerance test (OGTT) as per World Health Organization guidelines (WHO, 1999) with each child receiving oral glucose solution in the form of Top Star 75 at the rate of $1.75 \mathrm{gm} / \mathrm{kg}$ up to a maximum of 75 grams. Thereafter random blood sugar was taken using a hand held Accucheck glucometer from Roche inc, Basel - Switzerland at $0 \mathrm{hr}$ and 2 hours.

\section{Ethical Considerations}

Permission to conduct the study was sought and obtained from lubango pediatric hospital and the provincial Ethical committees. A written informed consent was obtained from the caretakers willing to participate in the study.

\section{Analysis}

A. Glucose intolerance was defined as an OGTT of > $7.8 \mathrm{mmol} / \mathrm{l}$, Insulin resistance was computed as $\mathrm{HO}$ MA-IR > 1.999 .

B. Descriptives analysis were undertaken for the parent/guardian and children characteristics with proportions reported for categorical variables while mean and standard deviation (SD) for continuous normally distributed data and median and inter-quartile ranges for skewed data.

C. The characteristics of the children were described using means and medians for continuous variables.

D. To explore for association and risk factors for glu- 
Table 1: Socio-Demographic characteristics of the Caretaker.

\begin{tabular}{|l|l|c|}
\hline Age group of guardian $\mathrm{n}(\%)$ \\
\hline & $<25$ years & $4(8)$ \\
\hline & $25-29$ yrs & $8(16)$ \\
\hline & $30-34$ yrs & $14(28)$ \\
\hline & $35-39$ yrs & $7(14)$ \\
\hline & $>=40$ yrs & $17(34)$
\end{tabular}

Marital status

\begin{tabular}{|c|c|c|}
\hline & Married & $20(40.0)$ \\
\hline & Single & $25(50.0)$ \\
\hline & Widowed & $5(10.0)$ \\
\hline \multicolumn{3}{|c|}{ Relationship to child } \\
\hline & Mother & $23(46.0)$ \\
\hline & Father & $3(6.0)$ \\
\hline & Stepmother & $2(4.0)$ \\
\hline & Sister & $3(6.0)$ \\
\hline & Maternal grandmother & $6(12.0)$ \\
\hline & Maternal grandfather & $4(8.0)$ \\
\hline & Others & $9(18.0)$ \\
\hline \multicolumn{3}{|l|}{ Residence } \\
\hline & Rural & $14(28.0)$ \\
\hline & Urban & $36(72.0)$ \\
\hline \multicolumn{3}{|l|}{ Religion } \\
\hline & Christian & $50(100.0)$ \\
\hline \multicolumn{3}{|l|}{ Education level } \\
\hline & None & $1(2.0)$ \\
\hline & Primary & $25(51.0)$ \\
\hline & Secondary/Technical & $22(44.9)$ \\
\hline & Tertiary & $1(2.0)$ \\
\hline \multicolumn{3}{|l|}{ Occupation } \\
\hline & Unemployed & $11(22.0)$ \\
\hline & Student & $3(6.0)$ \\
\hline & Self-Employed & $17(34.0)$ \\
\hline & Civil Servant & $10(20.0)$ \\
\hline & Others & $9(18.0)$ \\
\hline \multicolumn{3}{|l|}{ Income } \\
\hline & Below 50 USD & $16(35.6)$ \\
\hline & Above 50 USD & $29(64.4)$ \\
\hline
\end{tabular}

cose intolerance and/or insulin Resistance, a chisquare test was used. The dependent variables considered for the analysis included binary variables for HOMA-IR and or OGTT. Due to the limited number of observations (increasing chances of violation of the assumptions of the chi square e.g. the expected numbers of observations per cell were less than 5 , the fisher's exact test was used in estimating the
Table 2: Socio-Demographic characteristics of the children.

\begin{tabular}{|l|l|l|}
\hline Age group - child $\mathrm{n}(\%)$ & $<=5$ years & $9(18.0)$ \\
\hline & $6-7$ years & $8(16.0)$ \\
\hline & $8-10$ years & $17(34.0)$ \\
\hline & $11-15$ years & $16(32.0)$ \\
\hline Sex & Male & $26(52.0)$ \\
\hline & Female & $24(48.0)$ \\
\hline Schooling & \multicolumn{2}{|l|}{} \\
\hline & No & $17(21.4)$ \\
\hline & Yes & $33(66)$ \\
\hline Up to date immunization & \multicolumn{2}{|l|}{} \\
\hline & No & $3(6.0)$ \\
\hline & Yes & $47(94.0)$ \\
\hline Family history of diabetes & \multicolumn{2}{|l|}{} \\
\hline & No & $15(31.3)$ \\
\hline & Yes & \\
\hline & & \\
\hline & &
\end{tabular}

p-value.

E. Data Analysis was done using SPSS version 20 .

F. To ensure confidentiality all personal identifiers were left out of the data set.

\section{Results}

Between January and March 2019, a total of 50 participants (caretaker-child pair) were systematically recruited into the study. The majority of caretakers were the mother of the affected child $23 / 50$ (40\%), single $25 / 50$ (50\%), aged between 30 to 34 years 14/50 (28\%), living in an urban area 36/50 (72\%) and were Christian $50(100 \%)$, while one of the caretakers could not give properly his level of education and another one the monthly income (Table 1).

Among the 50 children recruited into the study, majority were aged between $8-10$ years $17 / 50$ (34\%), 26/50 (52\%) were male while 33/50 (66\%) attending school. Most children were fully immunized as per Angolan National immunization program 47 (94.0\%) and had no history of diabetes in their respective families 33/48 $(68.8 \%)$, while 2 of the caretakers could not exactly recall about the family history of diabetes (Table 2).

Majority of the children enrolled into the study were at stage I of the Tanner sexual development 18/24 (75.0\%) for females, and $18 / 26$ (69.2\%) for males. CD 4 cell count was more than $25 \%$ in $22 / 50$ (44.0\%) while majority of the children were at WHO stage I 28/50 (59.6\%) (Table 3).

Most children have been on ARV for between 1 to 2 years 16/50 (32\%), taking AZT/3TC/NVP 27/50 (54\%) and had a fasting blood glucose of 5.6-6.9 mmol// 34/50 (68\%) with a fasting insulin less than 4 micro unit/ml $26 / 50$ (52\%), while 20/50 (40\%) and 10/50 (20\%) had an 
OGTT and calculated HOMA-IR of more than $7.8 \mathrm{~mm} / \mathrm{I}$ and 1.999 respectively (Table 4).

Most children had a fasting blood sugar of 5.6-6.9

Table 3: Nutritional, clinical and Sexual characteristics of the child.

\begin{tabular}{|c|c|c|}
\hline Pubertal stage & & $\mathrm{n}(\%)$ \\
\hline & Male & $26(52.0)$ \\
\hline & Female & $24(48.0)$ \\
\hline \multicolumn{3}{|l|}{ Beast } \\
\hline & Stage 1 & $18(75.0)$ \\
\hline & Stage 2 & $6(25.0)$ \\
\hline \multicolumn{3}{|c|}{ Testicular volume } \\
\hline & Stage 1 & $18(69.2)$ \\
\hline & Stage 2 & $8(30.8)$ \\
\hline \multicolumn{3}{|c|}{ WHO clinical staging } \\
\hline & Stage 1 & $28(59.6)$ \\
\hline & Stage 2 & $10(21.3)$ \\
\hline & Stage 3 & $9(19.1)$ \\
\hline \multicolumn{3}{|l|}{ CD4 } \\
\hline & $<15 \%$ & $11(22.0)$ \\
\hline & $15 \%-25 \%$ & $17(34.0)$ \\
\hline & $>25 \%$ & $22(44.0)$ \\
\hline \multicolumn{3}{|c|}{$\begin{array}{l}\text { Age up to exclusive breast- } \\
\text { feeding }\end{array}$} \\
\hline$<=6$ months & & $42(91.3)$ \\
\hline$>6$ months & & $4(8.7)$ \\
\hline \multicolumn{3}{|c|}{ When breastfeeding stopped } \\
\hline$<=6$ months & & $3(6.5)$ \\
\hline 7-12 months & & $9(19.6)$ \\
\hline 13-24 months & & 32 (69.6) \\
\hline 24-36 months & & $2(4.3)$ \\
\hline \multicolumn{3}{|l|}{ BMI } \\
\hline & Normal & $35(70)$ \\
\hline & Underweight & $15(30)$ \\
\hline
\end{tabular}

\section{Series1,}

$>=7.0$

$\mathrm{mmol} / \mathrm{l}$,

$3(6 \%)$ $\mathrm{mmol} / \mathrm{l} 34 / 50$ (68\%); Figure 1 with a fasting insulin less than 4 micro unit/ml 26/50 (52\%); Figure 2, while 20/50 $(40 \%)$ and $10 / 50(20 \%)$ had an OGTT (Figure 3 ) and calculated HOMA-IR (Figure 4) of more than $7.8 \mathrm{~mm} / \mathrm{l}$ and 1.999 respectively.

Table 4: ARV Therapy and Glucose Metabolism.

\begin{tabular}{|c|c|c|}
\hline \multicolumn{3}{|l|}{ Duration of ARV n (\%) } \\
\hline & 1 year & $7(14)$ \\
\hline & $>1-2$ yrs & $16(32)$ \\
\hline & $3-4$ yrs & $5(10)$ \\
\hline & $5-10$ yrs & $10(20)$ \\
\hline & $>10$ & $12(24)$ \\
\hline \multicolumn{3}{|l|}{ ART Regiment } \\
\hline & ABC/3TC/EFV & $17(34)$ \\
\hline & $\mathrm{ABC} / 3 \mathrm{TC} / \mathrm{NVP}$ & $3(6)$ \\
\hline & AZT/3TC/EFV & $1(2)$ \\
\hline & AZT/3TC/NVP & $27(54)$ \\
\hline & $\mathrm{ABC} / 3 \mathrm{TC} / \mathrm{LPVr}$ & $2(4)$ \\
\hline \multicolumn{3}{|l|}{ Fasting blood glucose } \\
\hline & $<5.6 \mathrm{mmol} / \mathrm{l}$ & $13(26.0)$ \\
\hline & $5.6-6.9 \mathrm{mmol} / \mathrm{l}$ & $34(68.0)$ \\
\hline & $>=7.0 \mathrm{mmol} / \mathrm{l}$ & $3(6.0)$ \\
\hline \multicolumn{3}{|l|}{ Fasting insulin } \\
\hline & $<4$ micro unit/ml & $26(52.0)$ \\
\hline & 4-10 micro unit/ml & $19(38.0)$ \\
\hline & $>10$ micro unit $/ \mathrm{ml}$ & $5(10.0)$ \\
\hline \multicolumn{3}{|l|}{ OGTT } \\
\hline & $<7.8 \mathrm{mmol} / \mathrm{l}$ & $30(60.0)$ \\
\hline & $7.8-11 \mathrm{mmol} / \mathrm{l}$ & $17(34.0)$ \\
\hline & $>11.1 \mathrm{mmol} / \mathrm{l}$ & $3(6.0)$ \\
\hline \multicolumn{3}{|l|}{ HOMA categories } \\
\hline & $<=1.999$ & $40(80.0)$ \\
\hline & $>1.999$ & $10(20.0)$ \\
\hline
\end{tabular}

Series1, $<5.6$ $\mathrm{mmol} / \mathrm{l}, 13$

$(26 \%)$

Series1,

$<5.6 \mathrm{mmol} / \mathrm{l}$

5.6- 6.9

5.6- $6.9 \mathrm{mmol} / \mathrm{l}$

$\mathrm{mmol} / \mathrm{l}$,

$34(68 \%)$

$>=7.0 \mathrm{mmol} / \mathrm{l}$

Figure 1: Chart showing fasting sugar. 


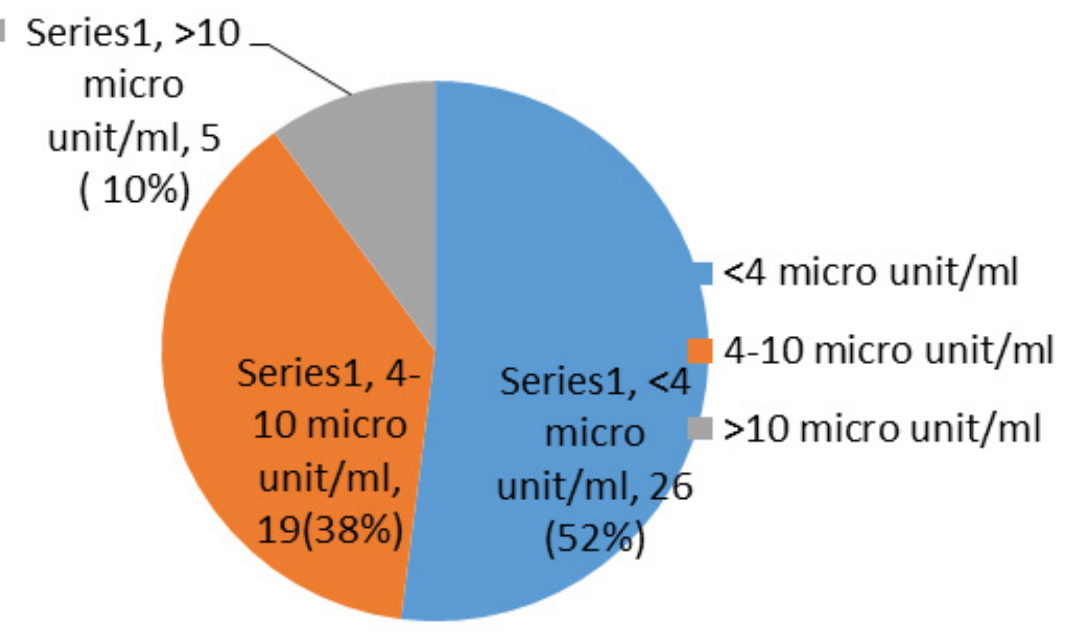

Figure 2: Chart showing fasting insulin.

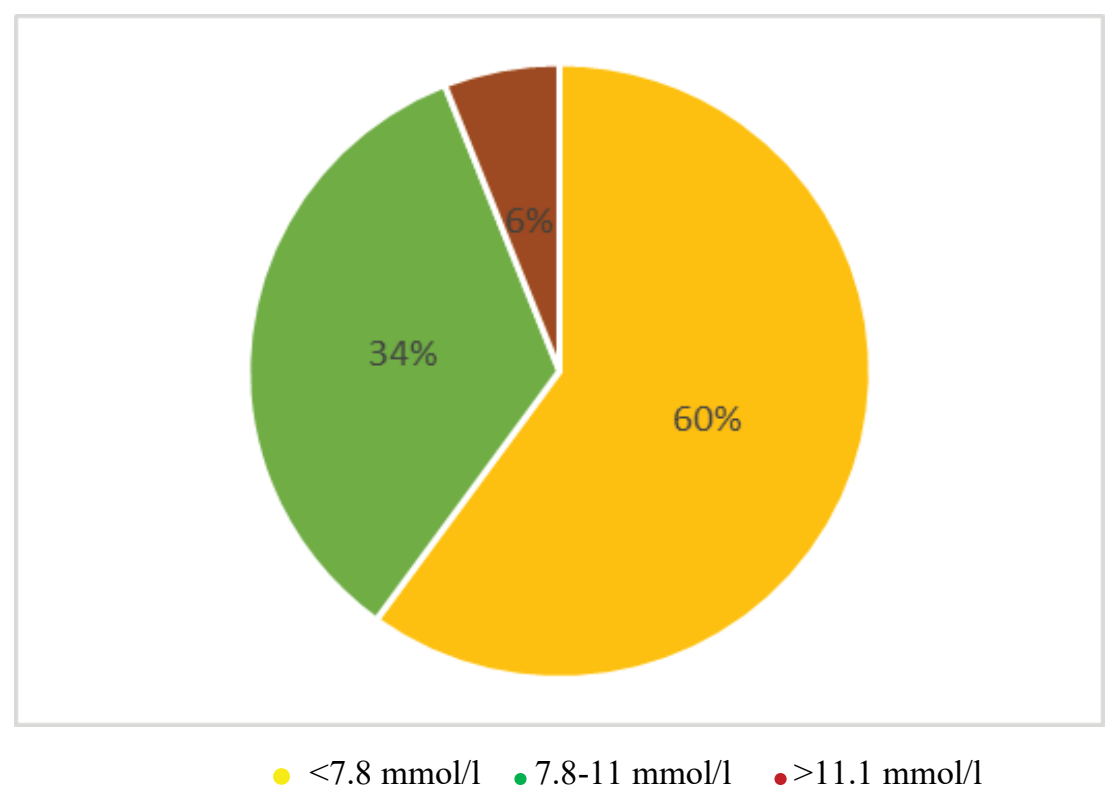

Figure 3: Chart showing OGTT.

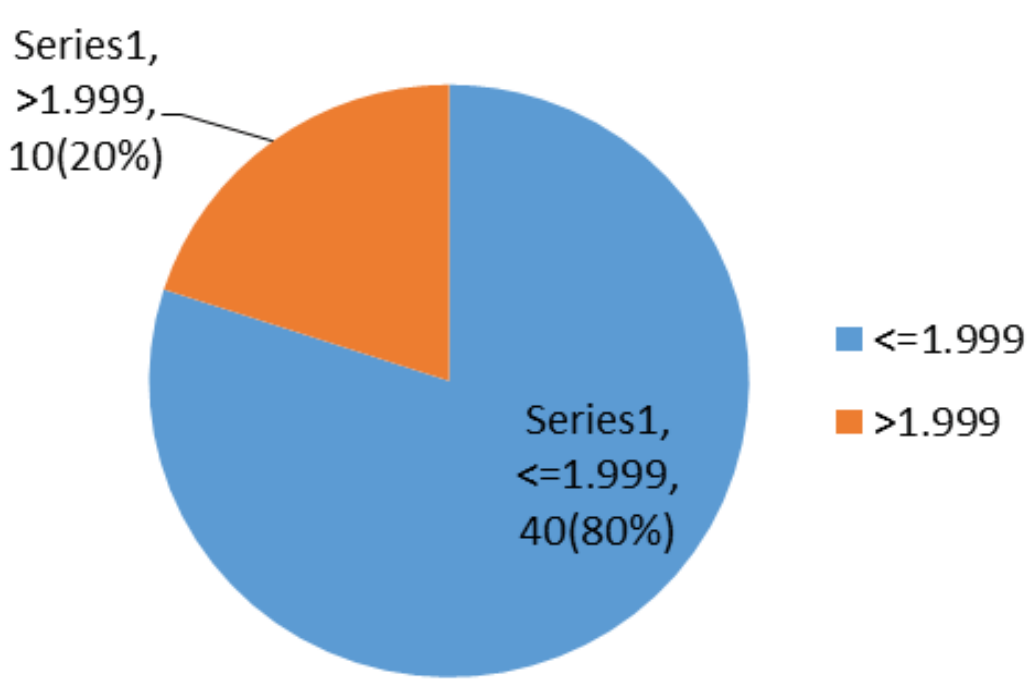

Figure 4: Chart showing HOMA-IR.

In the bivariate analysis, children who had history of diabetes in the family were significantly more likely to have Insulin Resistance (p 0.027) (Table 5). 
Table 5: Bivariate and multivariate analysis.

\begin{tabular}{|c|c|c|c|c|c|}
\hline & & $<=1.99(n=40)$ & $>1.99(n=10)$ & Chi value & $p$-value \\
\hline \multicolumn{6}{|c|}{ Demographics } \\
\hline \multirow[t]{5}{*}{ Age } & $<=5$ years & $8(18)$ & $1(10.0)$ & & \\
\hline & $6-7$ years & $8(20.0)$ & $0(0.0)$ & & \\
\hline & 8-10 years & $13(32.5)$ & $4(40.0)$ & & \\
\hline & $11-15$ years & $11(27.5)$ & $5(50.0)$ & & \\
\hline & & & & 3.80 & 0.280 \\
\hline \multicolumn{6}{|l|}{ Sex } \\
\hline & Male & $22(55.0)$ & $4(40.0)$ & & \\
\hline & Female & $18(45.0)$ & $6(60.0)$ & & \\
\hline & & & & 0.72 & 0.400 \\
\hline \multicolumn{6}{|c|}{ History of diabetes } \\
\hline & No & $29(76.3)$ & $4(40.0)$ & & \\
\hline & Yes & $9(23.7)$ & $6(60.0)$ & & \\
\hline & & & & 4.90 & 0.027 \\
\hline \multicolumn{6}{|c|}{ Pubertal stage } \\
\hline & male & $14(73.7)$ & $3(60.0)$ & & \\
\hline & female & $5(26.3)$ & $2(40.0)$ & & \\
\hline & & & & 0.36 & 0.550 \\
\hline \multicolumn{6}{|c|}{ Breast } \\
\hline & 1 & $15(78.9)$ & $3(60.0)$ & & \\
\hline & 2 & $4(21.1)$ & $2(40.0)$ & & \\
\hline & & & & 0.76 & 0.380 \\
\hline \multicolumn{6}{|c|}{ Testicular volume } \\
\hline & 1 & $16(76.2)$ & $2(40.0)$ & & \\
\hline & 2 & $5(23.8)$ & $3(60.0)$ & & \\
\hline & & & & 2.50 & 0.120 \\
\hline
\end{tabular}

Table 6: Bivariate and multivariate analysis: OGTT.

\begin{tabular}{|c|c|c|c|c|c|}
\hline & & \multicolumn{2}{|c|}{ OGTT categories } & \multirow[b]{2}{*}{ Chi Value } & \multirow[b]{2}{*}{$p$-value } \\
\hline & & $<7.8(n=30)$ & $>=7.8(\mathrm{n} 20)$ & & \\
\hline \multicolumn{6}{|c|}{ Demographics } \\
\hline \multirow[t]{5}{*}{ Age } & $<=5$ years & $6(20.0)$ & $3(15.0)$ & & \\
\hline & $6-7$ yrs & $5(16.7)$ & $3(15.0)$ & & \\
\hline & $8-10$ yrs & $12(40.0)$ & $5(25.0)$ & & \\
\hline & $11-15$ yrs & $7(23.3)$ & $9(45.0)$ & & \\
\hline & & & & 2.70 & 0.430 \\
\hline \multicolumn{6}{|l|}{ Sex } \\
\hline & Male & $12(40.0)$ & $14(70.0)$ & & \\
\hline & Female & $18(60.0)$ & $6(30.0)$ & & \\
\hline & & & & 4.30 & 0.038 \\
\hline \multicolumn{6}{|c|}{ History of diabetes } \\
\hline & No & $18(62.1)$ & $15(78.9)$ & & \\
\hline & Yes & $11(37.9)$ & $4(21.1)$ & & \\
\hline & & & & 1.50 & 0.220 \\
\hline \multicolumn{6}{|c|}{ Breast } \\
\hline & 1 & $14(82.4)$ & $4(57.1)$ & & \\
\hline & 2 & $3(17.6)$ & $3(42.9)$ & & \\
\hline & & & & 1.70 & 0.190 \\
\hline
\end{tabular}


Testicular volume

\begin{tabular}{|r|r|r|r|r|r|}
\hline & $11(84.6)$ & $7(53.8)$ & & \\
\hline & 2 & $2(15.4)$ & $6(46.2)$ & & \\
\hline
\end{tabular}

Table 7: Bivariate and multivariate analysis: OGTT

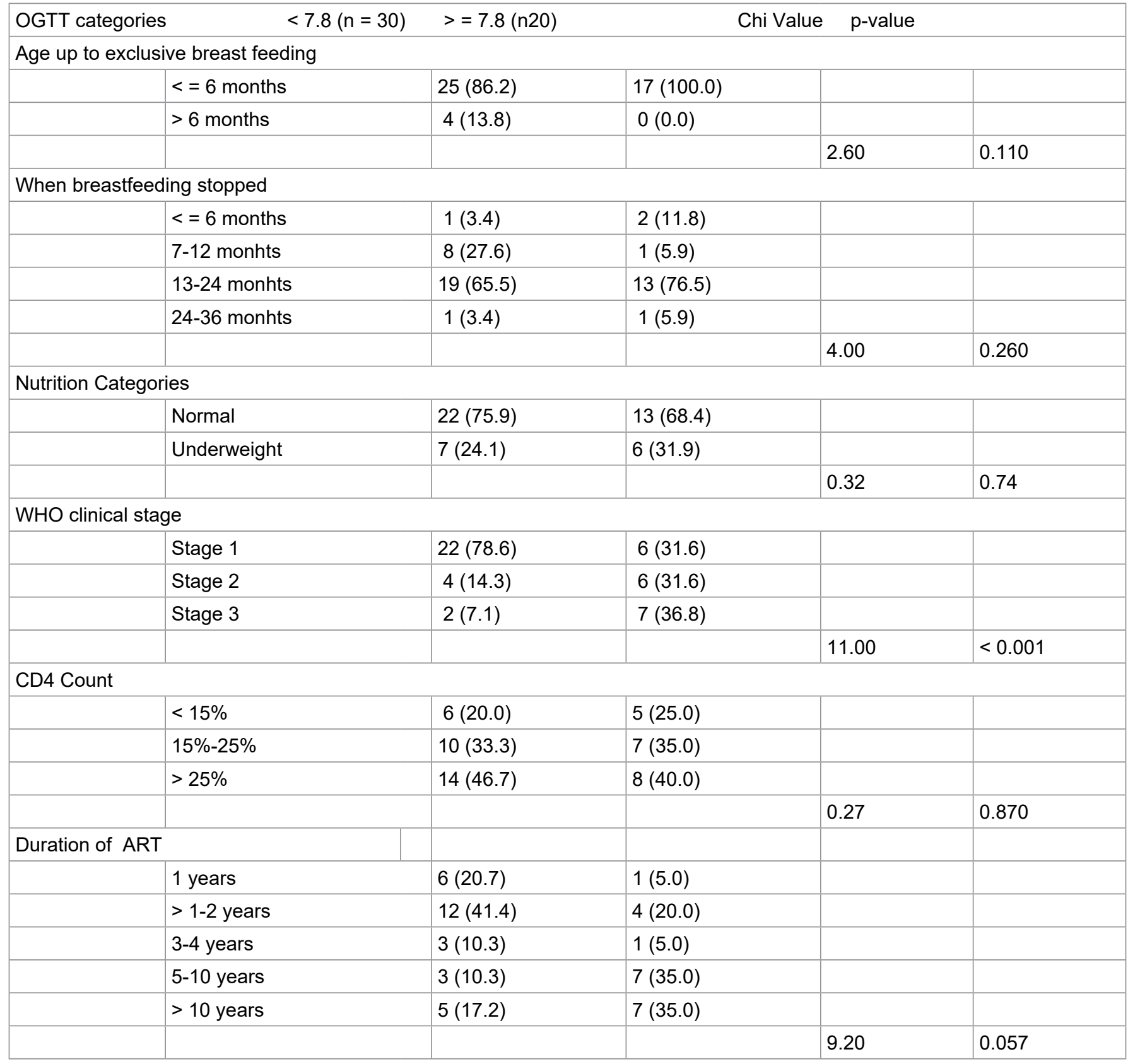

Among the socio-demographic and clinical characteristics studied, female sex ( $p$ 0.038) had a strong association with increase OGTT as shown in Table 6.

Advanced clinical stage of AIDS ( $p<0.001$ ) had a strong association with increase OGTT while long time on ARV was moderately associated with increased OGTT (p 0.057) as seen in Table 7.

\section{Discussion}

The introduction of ART has significantly improved the life expectancy of HIV infected individuals, changing the cause of death from infectious and neoplastic diseases to chronic diseases that are mediated by HIV or it treatment [10]. The primary objective of this facility-based study was to determine the pattern of Insulin Resistance and glucose intolerance among HIV infected children on ART being followed up at lubango pediatric Hospital. Overall, the prevalence of insulin resistance based on the Homeostatic Model Assessment for Insulin Resistance (HOMA-IR) was $20 \%$ while that for glucose intolerance was $40 \%$. These estimates are consistent with those reported in literature with the prevalence being reported in South Africa as $26 \%$ and $37 \%$ in HIV patients on NRTI's and Pls based regiment respectively [11], while Lee $B$, et al. reported a prevalence of insulin resistance ranging between $6.5 \%$ and $52 \%$ among HIV 
infected children on ART in Thailand [12]. This suggests the possible influence of ART or the disease process on glycaemic control. Evidence from literature suggests that there is an association of ART with the full spectrum of metabolic abnormalities and has included the ability PIs to directly and/or indirectly modify body fat composition, lipid profile, quality and quantity of Adipokine and other pro and anti-inflammatory mediators [8]. This has often been attributed to fat re-distribution linked to protease inhibitors. Further, the potential of Nucleoside Reverse Transcriptase Inhibitors (NRTIs) to alter Mitochondrial function and to influence insulin sensitivity has also been reported [9]. However, in this study only two children were on protease inhibitors limiting our ability to explore the association between protease inhibitors and metabolic abnormalities.

In our bivariate analysis, children who had history of diabetes in the family were significantly more likely to have Insulin Resistance ( $p$ 0.027) while gender was associated with increased OGTT ( $p$ 0.038). Similar findings have been reported by Ghosh, Hu and Khoury (2010) who also reported a family history of diabetes as an independent factor associated to metabolic syndrome including to glucose intolerance and insulin resistance [13], and Irving (2016) who found an association between a family history of early onset of type 2 diabetes and metabolic syndrome including insulin resistance in the offspring [14]. Independent of ART, genetic and environmental factors have been shown to be risk factors for metabolic syndromes. Therefore, when combined with genetic and some environmental risk factors, the use of Antiretroviral therapy may result to measurable changes in blood glucose pattern and insulin sensibility, which in some patient are sufficient enough to manifest as an overt Diabetes mellitus or other symptomatic metabolic abnormality [15].

Puberty is a time of considerable metabolic and hormonal change with associated marked decrease in insulin sensitivity, similar to that seen during pregnancy. In otherwise healthy youth, there is a low-point in insulin sensitivity in mid-puberty, and then it recovers at puberty completion. Our findings of a significant association between increased OGTT and gender ( $p$ 0.038) might therefore be explained by the link between puberty and the metabolic and hormonal changes during this period. Advanced clinical stage AIDS ( $p<0.001)$ and long time on ARV ( $p$ 0.057) were associated with increased OGTT. Similar findings were reported by Rafaella Rosso, et al. (2007) who found that the duration on ART was one of the predictors of insulin resistance among HIV infected children [16], clearly implication ART as one of the factors affecting insulin sensitivity and glucose tolerance in HIV infected patient. This highlights the need to not only link changes in insulin resistance and glucose intolerance to the effect of HIV on the metabolism of glucose and the side effects of ART but also consider to pubertal changes in the design of public health interventions especially for pre-teens.

\section{Limitations and Strengths}

Although this study collected patient level data on HIV infected children on ART and Insulin Resistance, these numbers were too few for generalization and as a cross sectional look a causal relationship cannot be imputed. Further, this study was undertaken in a tertiary hospital hence extrapolation of results is limited to hospitals with similar status.

Despite these limitations, being the only such study in Angola make our findings useful and relevant as a base line for a cohort study to determine the temporal distribution of the observed association.

\section{Conclusion}

The prevalence of insulin resistance among HIV positive children on follow up at lubango pediatrics Hospital, Angola based on the Homeostatic Model Assessment for Insulin Resistance (HOMA-IR) was $20 \%$ while that for based on OGTT was $40 \%$.

Children who had history of diabetes in the family were significantly more likely to have Insulin Resistance (p0.027) as calculated using HOMA-IR.

Factors significantly associated with increased OGTT among HIV positive children on ART on follow up at Lubango Paediatrics Hospital, were:

i. Female sex (p 0.038).

ii. Advanced clinical stage of the AIDS disease $(p<$ 0.001).

iii. Long time on ARV ( $p$ 0.057).

\section{Recommendations}

\section{Implications for policy and practice}

The transformation of HIV from deadly health condition into a manageable chronic disease by Antiretroviral therapy brings logically new emerging challenges in treating HIV infected Adults and principally children who are most frequently infected pre-nataly and logically will take these drugs for more years, including during pregnancy. Further, the introduction and implementation of the new WHO guidance of 'Test and Treat' means that even a higher number of children will be initiated on treatment early and hence prolonged duration of treatment that is also linked to better survival. Our findings suggest the need for periodic testing of insulin resistance for patients on ART (for instance once a year) to identify and address any comorbidities linked to glycaemic control at an early stage especially as more children survive to older ages.

\section{References}

1. Hadigan C, Kattakuzhy S (2016) Diabetes mellitus type 2 and abnormal glucose metabolism in the setting of human immunodeficiency. Endocrinol Metab Clin North Am 43: 685-696. 
2. Newell ML, Brahmbhatt $H$, Ghys PD (2004) Child mortality and HIV infection in Africa: A review. AIDS 18: 27-34.

3. Avy violari, F Mark F, Diana M Gibb, Abdel G Babiker, Steyn $\mathrm{J}$, et al. (2008) Early antiretroviral therapy and mortality among HIV infected infants. N Engl Med 359: 2233-2244.

4. Sarah Benki-Nugent, Michael J Boivin (2019) Neurocognitive complication of Pediatric HIV infection. Curr Pop Behave Neurosc.

5. Joint United Nations Programme on HIVIAIDS (2016) Get on the Fast-Track: The life-cycle approach to HIV. UNAIDS, Geneva, p 8.

6. Carr A, Samaras K, Thorisdottir A, Karifmann GR, Chrisholen DJ, et al. (1999) Diagnosis, prediction and natural course of HIV1 protease inhibitor associated lipodystrophy, hyperlipidemia and diabetes mellitus: A cohort study. Lancet 19: 2093-2099.

7. Lagathu C, Kim M, Maachi M, Vigouroux C, Cervera P, et al. (2005) HIV antiretroviral treatment alters adipokine expression and insulin sensitivity of adipose tissus in insulin sensitivity of adipose tissue in vitro and in vivo. Biochimie 87: 65-71.

8. Noor MA (2007) The role of protease inhibitors in the pathogenesis of HIV-associated insulin resistance: Cellular mechanisms and clinical implications. Curr HIVIAIDS Rep 4: 126-134.

9. Blumer RM, Vonderen MGV, Sutinen J, Hassink E, Ackermans M, et al. (2008) Zidovudine/Lamivudine contributes to insulin resistance within 3 months of starting combination antiretroviral therapy. AIDS 22: 227-236.
10. Pedro MN, Rocha GZ, Guadagnini D, Santos A, Magro DO, et al. (2018) Insuline resistance in HIV Patient: Causes and consequencs. Front Endocrinal (Lausanne) 9: 514.

11. Aboud M, Elgalib A, Kulasegaram R, Peters B (2007) Insulin resistance and HIV infection: A review. Int JClin Pract 61: 463-472.

12. Lee B, Aurpibul L, Sirisamtana V, Manglabrusks A, Sirisanthana, et al. (2009) Low prevalence of insulin resistance among HIV-infected children receiving NNRTI's based highly active antiretroviral therapy in Thailand. HIV Med 10: 72-78.

13. Ghosh A, Hu T, Khoury MJ, Valdez R (2010) Family history of diabetes and pevalnce of the metabolic syndrome in US adult without diabetes: 6 years results from the National Health and Nutrition examination survey (1999-2004). Public Health Genome 13: 353-359.

14. Irving R (2016) The metabilic syndrome in offspring of women with type 2 diabetes mellitus who developd gestational diabetes mellitus. American journal of cardiovascular disease research 4: 1-6.

15. Brown TT, Cole SR, Li X, Kingsley LA, Palella FJ, et al. (2005) Antiretroviral therapy and prevalence and incidence of diabetes mellitus in multicenter AIDS cohort. Arch Intr Med 165: 1179-1184.

16. Rosso R, Parodi A, D'Anmunzio G, Ginacchio F, Nicolini L, et al. (2007) Evalaution of insulin resistance in a cohort of infected youth. European Journal of Endocrinology 157: 655-659. 